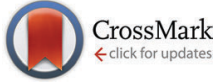

Cite this: New J. Chem., 2016, 40,4252

Received (in Montpellier, France) 27th October 2015, Accepted 18th January 2016

DOI: 10.1039/c5nj03001c

www.rsc.org/njc

\section{Synthesis and structure characterization of zinc and cadmium dipeptide coordination polymers $\dagger$}

\author{
Andreas Puškarić, ${ }^{* a}$ Ivan Halasz, ${ }^{b}$ Matija Gredičak, ${ }^{c}$ Ana Palčić ${ }^{a}$ and Josip Bronićc ${ }^{\star a}$ \\ Two new coordination polymers, Zn(Gly-L-Phe $)_{2}$ and $\mathrm{Cd}(\mathrm{Gly}-\mathrm{L}-\mathrm{Phe})_{2}(\mathrm{Gly}-\mathrm{L}-\mathrm{Phe}=$ glycyl-L-phenylalanine), \\ have been synthesized by the reaction of $\mathrm{Zn}\left(\mathrm{NO}_{3}\right)_{2} \cdot 6 \mathrm{H}_{2} \mathrm{O}$ or $\mathrm{Cd}\left(\mathrm{NO}_{3}\right)_{2} \cdot 6 \mathrm{H}_{2} \mathrm{O}, \mathrm{NaOH}$ and glycyl-L- \\ phenylalanine. The obtained materials were characterized by infrared spectroscopy, thermal analysis, \\ atomic absorption spectroscopy, while crystal structures were determined from powder X-ray diffraction \\ data. Both products crystallize in the chiral monoclinic C2 space group, having similar unit cell parameters, \\ forming a two-dimensional coordination network, two of which are interpenetrated giving a non-porous \\ structure. Both products show enhanced thermal stability (over $300^{\circ} \mathrm{C}$ ).
}

\section{Introduction}

Since the early 1990s a number of research teams started to extensively synthesise and characterise organic-inorganic hybrid materials of regular microporous structures..$^{1-5}$ Nowadays, coordination polymers and metal-organic frameworks (MOFs) are well known classes of compounds, where organic molecules are used as spacers (polydentate bridging ligands) between two (or more) inorganic parts (metal cations).

Due to their specific physico-chemical properties (porosity, high surface area, low density, structural and chemical diversity) MOFs could be used in a wide range of applications such as gas storage and/or separations $\left(\mathrm{CO}_{2}\right.$, methane, $\mathrm{H}_{2}$, $\mathrm{NO}_{X}$, etc.), catalysis (conversion of $\mathrm{CO}$ to $\left.\mathrm{CO}_{2}\right),{ }^{6}$ sensing devices (light harvesting, gases and temperature sensors, etc.). ${ }^{5}$ Recently, attention of the researchers in biomedicine was directed towards synthesis and use of "biofriendly" MOFs (it means biocompatible and less-harmful or at least non-toxic materials) in diagnostics (magnetic resonance imaging), and drug delivery. ${ }^{8}$ Their structure can be flexible to adopt foreign molecules, and vary in size of voids enabling a large number of possible MOFs of different structural features.

Numerous organic molecules such as amino acids, peptides, nucleobases, carbohydrates, and many other natural molecules

\footnotetext{
${ }^{a}$ Ruđer Bošković Institute (RBI), Division of Materials Chemistry, Bijenička 54, HR-10002 Zagreb, Croatia. E-mail: apuskar@irb.hr, bronic@irb.hr

${ }^{b}$ RBI, Division of Physical Chemistry, Bijenička 54, HR-10002 Zagreb, Croatia

${ }^{c}$ RBI, Division of Organic Chemistry and Biochemistry, Bijenička 54,

HR-10002 Zagreb, Croatia

$\dagger$ Electronic supplementary information (ESI) available. CCDC 1432895 and 1443402. For ESI and crystallographic data in CIF or other electronic format see DOI: $10.1039 / \mathrm{c} 5 \mathrm{nj} 03001 \mathrm{c}$
}

represent excellent ligands for the synthesis of biocompatible MOFs. ${ }^{78}$ At the same time, $\mathrm{Ca}, \mathrm{Mg}, \mathrm{Zn}, \mathrm{Fe}, \mathrm{Cu}$ and Ti are metals that can be used as inorganic cations for the synthesis of the mentioned MOFs.

Amino acids and peptides are molecules which have several "active sites" (-COO, $-\mathrm{NH}_{2}$, and some side chain groups) where metal cations can be attached to form different MOFs. Because of their disposition/availability and molecule chirality, they have received notable attention as potential ligands. At the same time, great disadvantage of the use of the peptides as ligands comes from the fact that the synthesis of crystals from solutions can be hard, due to the thermodynamically non-favorable formation of the crystalline phase and its purity. ${ }^{9}$

Recently, Rosseinsky and coworkers have synthesized several rigid and flexible metal-dipeptide frameworks $\left[\mathrm{Zn}(\text { Gly-L-Ala })_{2}\right] \cdot($ solvent $),{ }^{10}\left[\mathrm{Zn}(\mathrm{Gly}-\mathrm{L}-\mathrm{Thr})_{2}\right] \cdot \mathrm{CH}_{3} \mathrm{OH},{ }^{11} \mathrm{Zn}(\mathrm{Gly}-$ L-Ser $)_{2} \cdot 2 \mathrm{CH}_{3} \mathrm{OH}^{12}$ and $\left.\mathrm{Zn}(\beta \text {-Ala-L-His })^{13}\right)$ with permanent porosity. It was shown that different structures, with distinct adsorption properties, can be synthesized by slightly changing the side chain group of the peptide. For example, ([Zn(Gly-L-Ala $\left.)_{2}\right]$ is flexible and has adaptable porosity while $\left[\mathrm{Zn}(\mathrm{Gly}-\mathrm{L}-\mathrm{Thr})_{2}\right]$ exhibits a rigid porous framework. Hydrogen bonding, arising from the - $\mathrm{OH}$ group of threonine, is responsible for stability even after the removal of the remaining solvent molecules.

On the other hand, thermal stability as well as consistency in water is one of main research issues in the metal-peptide polymer chemistry.

So, the main idea of this work was to use a relatively large side chain part of dipeptide molecules, with ability to stabilize the synthesized product - a new metal-dipeptide MOF of enhanced properties: resistance to water solubility, greater thermal stability, and structure flexibility. 


\section{Experimental}

\section{Materials and methods}

All chemicals were of analytical grade and have been used as received, without further purification. Enantiomerically pure $\mathrm{H}$-Gly-L-Phe-OH was acquired from Bachem, $\mathrm{Zn}\left(\mathrm{NO}_{3}\right)_{2} \cdot 6 \mathrm{H}_{2} \mathrm{O}$, $\mathrm{ZnCl}_{2}, \mathrm{ZnBr}_{2}, \mathrm{Cd}\left(\mathrm{CH}_{3} \mathrm{COO}\right)_{2} \cdot 2 \mathrm{H} \mathrm{H}_{2} \mathrm{O}, \mathrm{CdI}_{2}, \mathrm{Cd}\left(\mathrm{NO}_{3}\right)_{2} \cdot 4 \mathrm{H}_{2} \mathrm{O}$ and $\mathrm{NaOH}$ from commercial sources. Powder XRD data were collected on a Phillips PW3710 diffractometer with $\mathrm{CuK}_{\alpha}$ source. FT-IR spectra were recorded on a Bruker TENSOR 37 spectrometer using $\mathrm{KBr}$ pellets, in the range from 400 to $4000 \mathrm{~cm}^{-1}$. Thermogravimetric measurements were performed under air, with a heating rate of $10{ }^{\circ} \mathrm{C} \min ^{-1}$ using a Shimadzu DTG-60H instrument. Metal content was determined by atomic absorption spectrometry on Perkin Elmer's AAnalyst 200. Scanning electron micrographs were recorded using Tescans' MIRA-LMH SEM instrument. Elemental (CHN) analysis was performed on a Perkin Elmer 2400 Series II CHNS System.

Synthesis of $\mathbf{Z n}(\text { Gly-L-Phe })_{2}$. The synthesis procedure was adopted from ref. 10 and slightly modified. Dipeptide H-Gly-LPhe-OH (66.7 mg, $0.3 \mathrm{mmol}$ ) was dissolved in $2 \mathrm{~mL}$ of aqueous solution of $\mathrm{NaOH}\left(c=0.1 \mathrm{~mol} \mathrm{dm}^{-3}\right) .1 .5 \mathrm{~mL}$ of methanol solution of $\mathrm{Zn}\left(\mathrm{NO}_{3}\right)_{2} \cdot 6 \mathrm{H}_{2} \mathrm{O}\left(c=0.1 \mathrm{~mol} \mathrm{dm}{ }^{-3}\right)$ was added to dipeptide solution. The reaction mixture was diluted with $4 \mathrm{~mL}$ of deionized water and $4.5 \mathrm{~mL}$ of methanol. Clear reaction solution was transferred to a Teflon-lined autoclave, heated for $48 \mathrm{~h}$ at $85{ }^{\circ} \mathrm{C}$ and left to slowly cool down in the oven. White, thin, platelike crystals were isolated by filtration and washed with small portions of methanol (yield $=77 \%$ ).

Synthesis of Cd(Gly-L-Phe) $)_{2}$. Dipeptide $(66.7 \mathrm{mg}, 0.3 \mathrm{mmol})$ was dissolved in $1.5 \mathrm{~mL}$ of aqueous solution of $\mathrm{NaOH}\left(c=0.1 \mathrm{~mol} \mathrm{dm}^{-3}\right)$ and $4.5 \mathrm{~mL}$ of water was added. Then to dipeptide solution, $6 \mathrm{~mL}$ of aqueous $\mathrm{Cd}\left(\mathrm{NO}_{3}\right)_{2} \cdot 4 \mathrm{H}_{2} \mathrm{O}$ solution $\left(c=0.025 \mathrm{~mol} \mathrm{dm}{ }^{-3}\right)$ was added. Immediately after adding the cadmium solution to the dipeptide, the reaction solution became milky. The reaction mixture was heated in screw cap vial for $48 \mathrm{~h}$ at $85{ }^{\circ} \mathrm{C}$ and left to slowly cool down in the oven. White rodlike crystals were isolated by filtration and washed with small portions of water (yield $=77 \%$ ).

\section{Results and discussion}

\section{Synthesis}

The solvothermal reaction of $\mathrm{Zn}^{2+}$, H-Gly-L-Phe-OH, and $\mathrm{NaOH}$ in mixture of water and methanol gave a crystalline product [Zn(Gly-L-Phe $\left.)_{2}\right]$ (1). Obtained crystals are composed of thin plates and small pieces of the same material at their surface (Fig. 1), which were not appropriate for single crystal X-ray diffraction measurements. The reaction of cadmium(II), Gly-L-Phe, and $\mathrm{NaOH}$ in water gave a microcrystalline product, $\left[\mathrm{Cd}(\mathrm{Gly}-\mathrm{L}-\mathrm{Phe})_{2}\right](2)$. Rodlike crystals (Fig. 1) were also inappropriate (they are too small) for single crystal X-ray diffraction. To get crystals suitable for single crystal X-ray diffraction, layer-to-layer diffusion of reactants and vapor diffusion of triethylamine into the reaction mixture were performed. However, both methods gave only a microcrystalline product.

The influence of synthesis parameters (temperature, reactant ratio, metal source) was also examined. Increase of the reaction
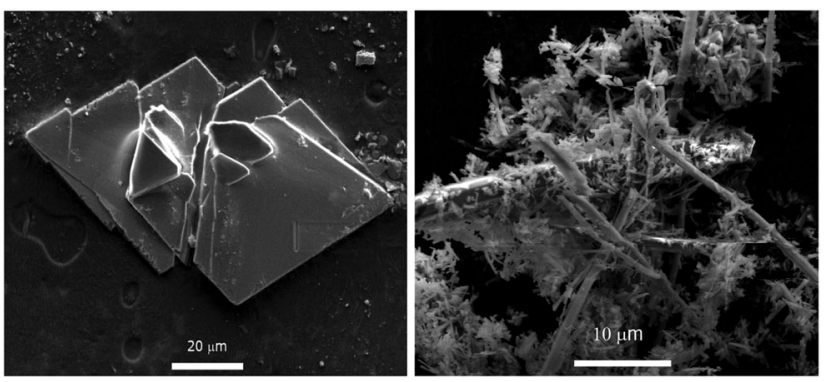

Fig. 1 SEM photos of Zn(Gly-L-Phe) ${ }_{2}$ (left) and Cd(Gly-L-Phe) ${ }_{2}$ (right).

temperature to $120{ }^{\circ} \mathrm{C}$ or above in the main system (the ratio $\mathrm{Zn}$ : dipeptide $: \mathrm{NaOH}=1: 2: 2$ ) causes partial decomposition of dipeptide and gives an unidentified product along with $\mathrm{ZnO}$ (denoted by ${ }^{*}$ on XRD patterns in Fig. S1, ESI $\dagger$ ).

An increase of the alkalinity of the main system (the ratio Me : dipeptide $: \mathrm{NaOH}=1: 2: 2.5)$ causes the formation of $\mathrm{ZnO}$ or $\mathrm{Cd}(\mathrm{OH})_{2}$ as impurities alongside products 1 and 2, respectively (Fig. S2 and S3, ESI $\dagger$ ). A reaction system with metal to dipeptide ratios of $2: 1,1: 1$ and $1: 2$ at lower alkalinity $(<2)$ of the main system (at $85{ }^{\circ} \mathrm{C}$ ) gives pure crystalline product 1 or 2 .

Furthermore, the source of metal ions was also investigated. For zinc systems, use of chloride and bromide changes the morphology of $\mathbf{1}$ from platelike to rodlike, while acetate did not affect the morphology of the product. In the case of use of cadmium salts, acetate and iodide salts gave crystalline product 2 , without changes in the morphology of the product.

\section{Chemical composition}

Good agreement between theoretical and measured values obtained by CHN analysis (Table 1) is supplemented by thermo-gravimetric measurements presented in Fig. 2. TG and DTG data show that both polymers 1 and 2 remain stable to approximately $300{ }^{\circ} \mathrm{C}$, when they start to decompose with biggest mass loss at $347^{\circ} \mathrm{C}$ for 1 and $334{ }^{\circ} \mathrm{C}$ for 2 .

Decomposition of 1 ends at $500{ }^{\circ} \mathrm{C}$, leaving $\mathrm{ZnO}$ as the final product ( $16 \%$ of initial mass remained), what gives a zinc to dipeptide ratio of $1: 2$. Good agreement for the same ratio was calculated from AAS data; the obtained value is $12.7 \mathrm{wt} \%$ of $\mathrm{Zn}$, while the theoretical value is $12.8 \mathrm{wt} \%$ of $\mathrm{Zn}$. Decomposition of 2 ends at slightly lower temperature than $1\left(460{ }^{\circ} \mathrm{C}\right.$ ) with $27.4 \%$ mass left (CdO), what gives cadmium to dipeptide ratio of $1: 2$. Cadmium content in 2 is well corroborated with AAS data; the

Table 1 Chemical composition of the calculated (theoretical values for formulae: $\mathrm{C}_{22} \mathrm{H}_{26} \mathrm{~N}_{4} \mathrm{O}_{3} \mathrm{Zn}$ and $\mathrm{C}_{22} \mathrm{H}_{26} \mathrm{~N}_{4} \mathrm{O}_{3} \mathrm{Cd}$ ) and measured values of the samples obtained by $\mathrm{CHN}$ analysis, shown as wt\%

\begin{tabular}{|c|c|c|c|}
\hline & $\mathrm{C}$ & $\mathrm{H}$ & $\mathrm{N}$ \\
\hline $\mathrm{Zn}(\text { Gly-L-Phe })_{2}{ }^{a}$ & 52.03 & 5.16 & 11.03 \\
\hline $\mathrm{Zn}$ (Gly-L-Phe $)_{2}{ }^{b}$ & 51.97 & 5.59 & 10.89 \\
\hline Cd(Gly-L-Phe $)_{2}^{a}$ & 47.62 & 4.72 & 10.10 \\
\hline Cd(Gly-L-Phe $)_{2}^{b}$ & 47.55 & 4.96 & 9.97 \\
\hline
\end{tabular}

${ }^{a}$ Calculated values. ${ }^{b}$ Measured values. 


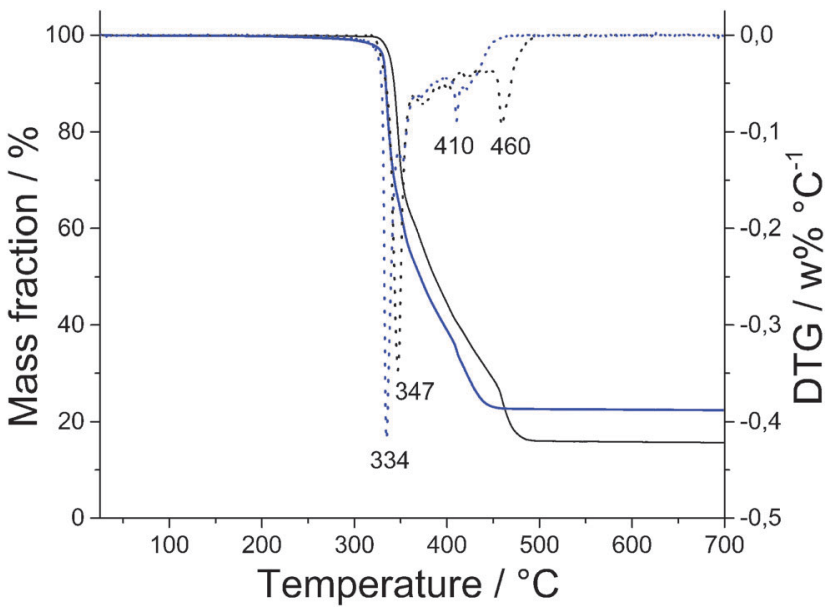

Fig. 2 TG curves of Zn(Gly-L-Phe) ${ }_{2}$ (black line), Cd(Gly-L-Phe) $)_{2}$ (blue line) and corresponding DTG curves (dotted lines).

theoretical value is $20.3 \mathrm{wt} \%$ of $\mathrm{Cd}$, while the measured value is $20.4 \mathrm{wt} \%$ of $\mathrm{Cd}$.

The thermal stability of similar MOFs, consisting only of dipeptides as linkers, are mainly up to $250{ }^{\circ} \mathrm{C},{ }^{10-13}$ but recently, $\mathrm{Co}(\mathrm{Gly}-\mathrm{L}-\mathrm{Glu})_{2}$ was synthesized having thermal stability up to $400{ }^{\circ} \mathrm{C}^{14}$

\section{Structure determination}

Since single crystals could not be obtained even by varying several reaction parameters, structure determination had to be done using a combination of powder diffraction data and chemical information, obtained by various techniques such as IR spectroscopy, thermal analysis and atomic absorption spectroscopy.

The IR spectra of the starting dipeptide, products 1 and 2, are shown in Fig. 3. In the free dipeptide, a broad band from $2000-3400 \mathrm{~cm}^{-1}$ is assigned to the combination of symmetric and asymmetric stretching $\mathrm{N}-\mathrm{H}, \mathrm{C}-\mathrm{H}$ vibrations, including intra- $\left(\mathrm{N}-\mathrm{H} \cdots \mathrm{O}_{\text {amide }}\right)$ and intermolecular $\left(\mathrm{N}-\mathrm{H} \cdots \mathrm{O}_{\text {carboxylate }}\right)$ hydrogen bonds. ${ }^{15-18}$ Coordination of dipeptide with metal atoms leads to the disappearance of the band at $2111 \mathrm{~cm}^{-1}$ and the aforementioned broad band became much narrower. Doublet at 3254 and $3212 \mathrm{~cm}^{-1}$ in the IR spectra of 1 became sharper, unlike in the IR spectra of 2 . These peaks are assigned to $\mathrm{N}-\mathrm{H}$ stretching vibration of the $\mathrm{NH}_{2}$ group corresponding to symmetric and antisymmetric modes. Sharp peaks at 3326 and $3337 \mathrm{~cm}^{-1}$ for $\mathbf{1}$ and 2 correspond to $\mathrm{N}-\mathrm{H}$ amide stretching vibration, which was not present in free dipeptide, due to the hydrogen bonds. $\mathrm{C}=\mathrm{O}$ amide stretching and $\mathrm{N}-\mathrm{H}$ bending bands were shifted from 1686 and $1628 \mathrm{~cm}^{-1}$ in free dipeptide to 1672 and $1601 \mathrm{~cm}^{-1}$ for 1 and to 1666 and $1601 \mathrm{~cm}^{-1}$ for 2 . Carboxylate asymmetric vibration appears at $1570 \mathrm{~cm}^{-1}$, while the position of the symmetric vibration bond is uncertain due to overlapping of bands.

Microcrystalline samples were gently ground and deposited into an $\mathrm{Al}$ holder. Diffraction data (graphite monochromated $\mathrm{CuK}_{\alpha}$ radiation) were collected for $8 \mathrm{~h}$ in the $2 \theta$ range $5-80^{\circ}$,

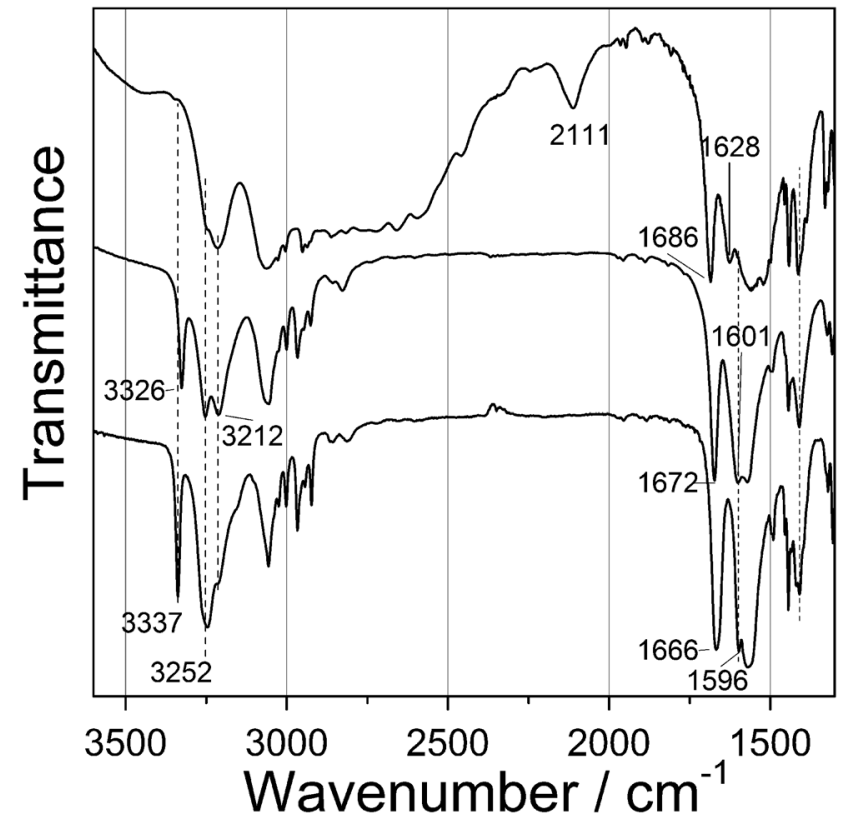

Fig. 3 FTIR spectra of initial dipeptide (Gly-L-Phe, top spectrum); Zn(Gly-L-Phe) 2 (middle spectrum); and Cd(Gly-L-Phe) 2 (bottom spectrum).

and step size of $0.02^{\circ}$. All calculations (peak search, indexing, structure solution and Rietveld refinement) were carried out using the TOPAS software. ${ }^{19}$

The diffraction pattern of $\mathbf{1}$ was indexed giving a monoclinic unit cell $\left(a=29.4580 \AA\right.$, $b=5.3011 \AA, c=7.4989 \AA, \beta=95.6024^{\circ}$, $V=1168.2 \AA^{3}$ ) with a figure of merit of 26.07. Systematic maxima absences suggested $\mathrm{C} 2, \mathrm{Cm}$ and $\mathrm{C} 2 / \mathrm{m}$ as probable space groups. Following the fact that the starting dipeptide is a pure chiral compound, $C 2$ space group was selected. The background was modeled with Chebyshev function and peaks shape with fundamental parameters. Unit cell and profile refinement were carried out using the Pawley method, ${ }^{20}$ which gave good agreement $R_{\mathrm{wp}}=0.1507, R_{\mathrm{p}}=0.1140$. Structure solution was performed by the simulated annealing technique, implemented in TOPAS. Dipeptide was input as the rigid body having translational and rotational degrees of freedom with torsion angles as variables. A zinc atom was entered independently with translational degrees of freedom. Simulated annealing gave sensible solution in which the $\mathrm{Zn}$ atom was found at the special position and linked to dipeptide. The obtained structural model gave a good fit to the experimental pattern, and it was introduced into Rietveld refinement. ${ }^{21}$ For Rietveld refinement, the dipeptide moiety was again treated as a rigid body, and the $y$ coordinate of the $\mathrm{Zn}$ atom was refined while $x$ and $z$ coordinates were fixed by symmetry of the special position. Two different isotropic temperature factors were included in refinement: one for the $\mathrm{Zn}$ atom and another for all other atoms. Preferred orientation was modeled using spherical harmonics function. The final Rietveld refinement plot is shown in Fig. 4, while crystallographic and refinement data are reported in Table $\mathrm{S} 1$ (ESI $\dagger$ ).

The same procedure, for the structure determination of Cd(Gly-L-Phe $)_{2}$, was used. The diffraction pattern of 2 was indexed 


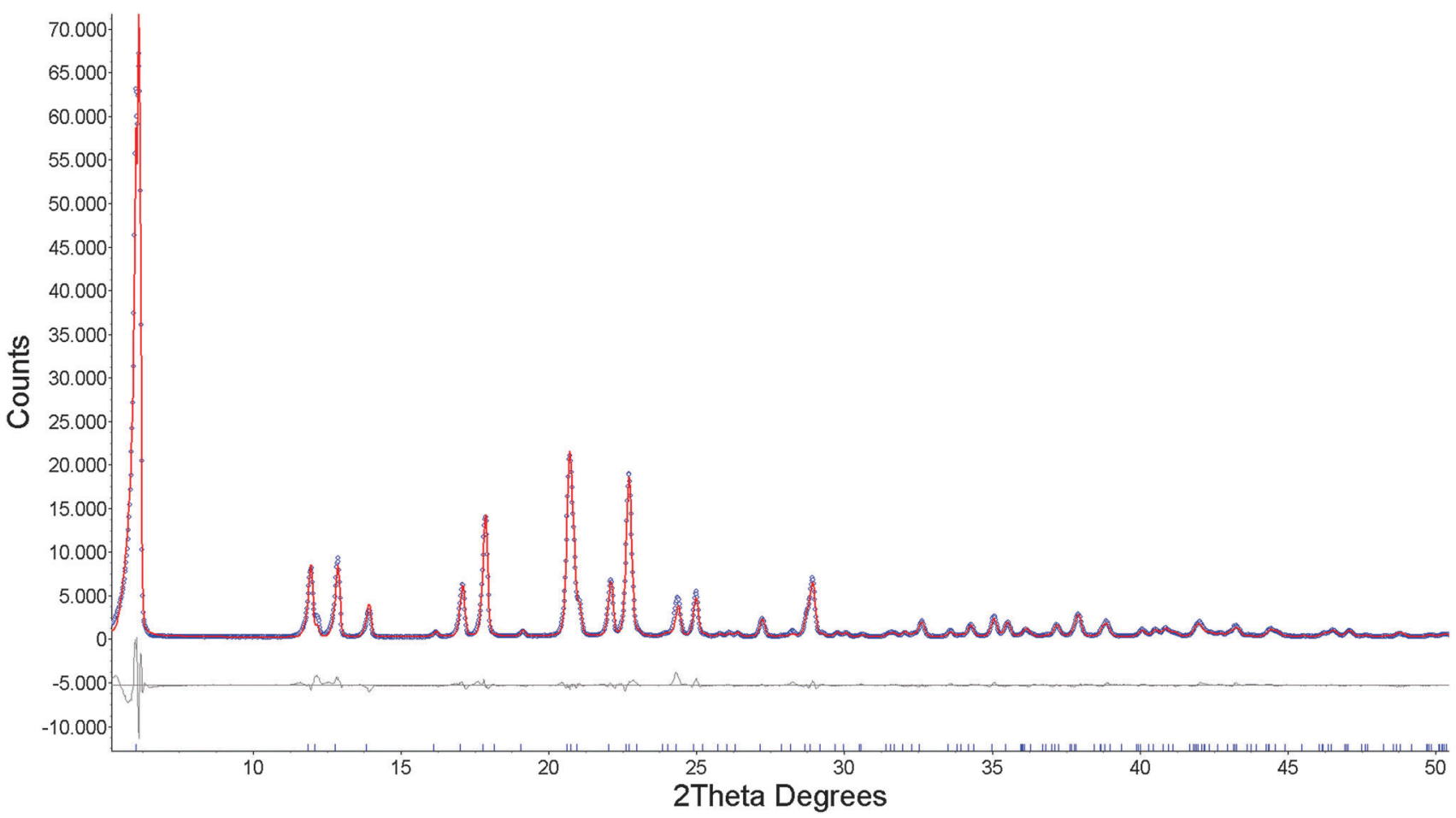

Fig. 4 Rietveld refinement plot of $\mathrm{Zn}(\mathrm{Gly}-\mathrm{L}-\mathrm{Phe})_{2}$ to $2 \theta=50^{\circ}$. Experimental data are shown by blue circles, calculated values by red line, and the difference by a grey line profile. Blue tick marks at the bottom indicate reflection positions.

giving a monoclinic unit cell with the following parameters: $a=30.5011 \AA, b=5.3419 \AA, c=7.6336 \AA, \beta=111.3530^{\circ}$, $V=1158.4 \AA^{3}$ (figure of merit 30.18). Systematic maxima absences suggested $C$ centered lattice with $\mathrm{C} 2, \mathrm{Cm}$ and $\mathrm{C2} / \mathrm{m}$ as probable space groups. Since the starting dipeptide is a pure chiral compound, $C 2$ space group was selected. Background was modeled with Chebyshev function and peaks shape with fundamental parameters. Unit cell and profile refinement were carried out using the Pawley method which gave excellent agreement $R_{\mathrm{wp}}=0.0684, R_{\mathrm{p}}=0.0491$. Structure solution was performed by the simulated annealing technique, implemented in TOPAS. As in case of $\mathbf{1}$, dipeptide was input as a rigid body having translational and rotational degrees of freedom with torsion angles as variables. A cadmium atom was entered independently with translational degrees of freedom. Simulated annealing gave rational solution in which the $\mathrm{Cd}$ atom was found at the special

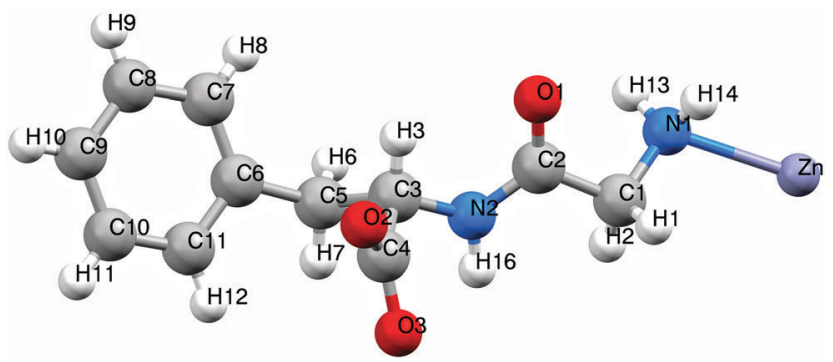

Fig. 5 Asymmetric unit of Zn(Gly-L-Phe) 2. Color notation: white - H, red - O, purple - Zn, blue - N, grey - C. position and linked to dipeptide. The obtained structural model gave a good fit to the experimental pattern and it was introduced into Rietveld refinement. For Rietveld refinement, the dipeptide moiety was again treated as a rigid body and the $y$ coordinate of the $\mathrm{Cd}$ atom was refined, while $x$ and $z$ coordinates were fixed by symmetry of the special position. Isotropic temperature factors and preferred orientation were included in refinement as in structure determination of $\mathbf{1}$. The final Rietveld refinement plot is shown in Fig. S4 (ESI $\dagger$ ), while crystallographic and refinement data are reported in Table S1 (ESI $\dagger$ ).

\section{Crystal structure of $\mathrm{Zn}(\text { Gly-L-Phe })_{2}$}

The asymmetric unit of $\mathbf{1}$ consists of a zinc(II) ion bonded to one dipeptide via the monodentate amino group of the glycyl moiety (Fig. 5). The zinc(II) ion is tetrahedrally coordinated: twice through amino groups of the glycine moiety and twice through carboxylate groups of the phenylalanine moiety. Both amino and carboxylate groups are in monodentate coordination mode. $\mathrm{Zn}-\mathrm{N}$ distance is $2.266 \AA$, and $\mathrm{Zn}-\mathrm{O}$ distance is $2.128 \AA$, which are in accordance with distances in similar compounds. ${ }^{11}$

Dipeptide ligands bridge zinc atoms giving rise to a twodimensional coordination polymer. Two types of hydrogen bonds connect/stabilize adjacent coordination polymers (Fig. 6 and Fig. S5,

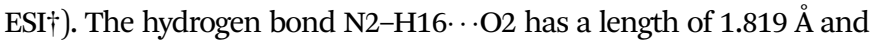
a bond angle $\mathrm{N} 2-\mathrm{H} 16-\mathrm{O} 2$ of $161.1^{\circ}$. The second hydrogen bond, $\mathrm{N} 1-\mathrm{H} 14 \cdots \mathrm{O} 3$, which includes the terminal amino group and coordinated carboxylate oxygen, is significantly longer $(2.405 \AA)$ with smaller bond angle $\left(150.5^{\circ}\right)$. Those parameters show that bond $\mathrm{N} 2-\mathrm{H} 16 \cdots \mathrm{O} 2$ is stronger and its contribution to structure 


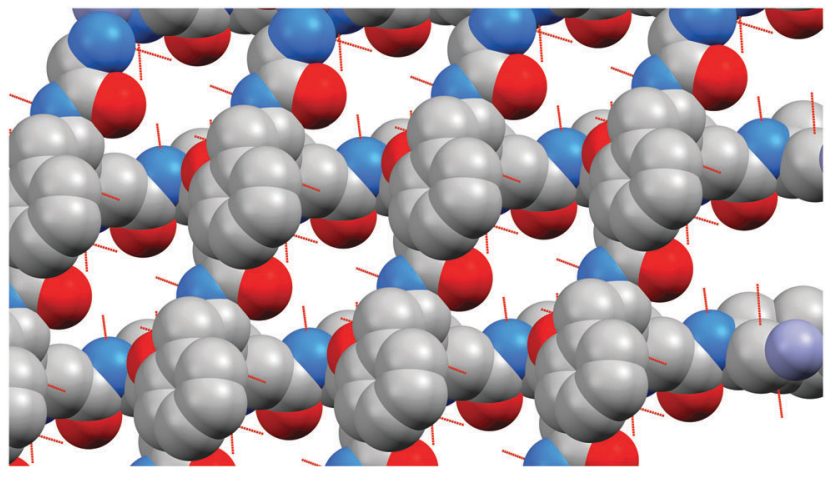

Fig. 6 A part of $\mathrm{Zn}(\mathrm{Gly}-\mathrm{L}-\mathrm{Phe})_{2}$ network showing directions of $\mathrm{H}$ bonds, which are connected to another part of the structure (not shown here) making an interpenetrated structure. Color notation: white - $\mathrm{H}$, red - $\mathrm{O}$, purple - Zn, blue - N, grey - C.

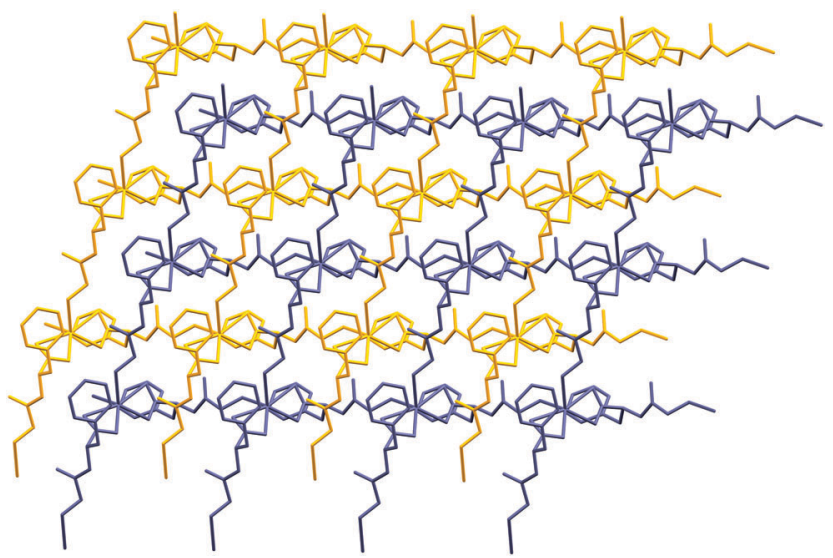

Fig. 7 Interpenetrated structure of the $\mathrm{Cd}(\mathrm{Gly}-\mathrm{L}-\mathrm{Phe})_{2}$ network. $\mathrm{H}$ atoms were omitted for clarity.

stabilization is more pronounced than the N1-H14 ‥O3 hydrogen bond. It is not surprising because the $\mathrm{O} 3$ atom is already bonded (coordinated) to zinc.

Coordination polymers propagate in two dimensions forming a square grid network with 4,4 topology in which potential pores are occupied by another neighbouring part of the peptide chain, thus giving an interpenetrated framework (for 1 - Fig. S6, ESI, $\dagger$ for 2 - Fig. 7). In the structure, phenyl rings are oriented in such a way, forming hydrophobic sheets, which enhance stability towards water (Fig. S7, ESI $\dagger$ ). At the same time, large side chain groups fill the intramolecular space, reducing the microporosity of the crystals.

\section{Crystal structure of Cd(Gly-L-Phe) $)_{2}$}

The asymmetric unit of 2 comprises of a cadmium ion bidentately linked to one molecule of dipeptide via the carboxylate group of the phenylalanine moiety (Fig. S8, ESI $\dagger$ ). Cadmium is hexacoordinated by four dipeptide ligands of which two are bonded through amino groups of glycine, while two carboxylate groups are chelating, as mentioned above. Dipeptide ligands are $\mu^{2}$ bridging as in 1. While the distance between Cd and O3 is $2.288 \AA$, what is in agreement with metal-peptide framework compounds in ref. 22, distances Cd-O2 (2.599 ̊̊) and Cd-N1 (2.485 $)$ are little longer than usual, indicating possibly weaker bonding. Hydrogen bonds are also present in this structure. Interaction between $\mathrm{N} 2-\mathrm{H} 16 \cdots \mathrm{O} 2$ ( $\mathrm{N}-\mathrm{H}$ from the peptide bond) has a length of $1.918 \AA$ and a bond angle of 165.4. Other hydrogen bond is between the terminal amino group and O3 having a distance of $2.097 \AA$ and a bond angle of $150.9^{\circ}$. The similarity of structural elements, and hydrogen bonds, of products 1 and 2 results in an isostructural twofold interpenetrated network (Fig. 7 and Fig. S6, ESI $\dagger$ ).

\section{Conclusions}

Two novel coordination polymers composed of zinc or cadmium and glycyl-L-phenylalanine were synthesized and characterized using various techniques. Crystal structures were determined and refined from powder diffraction data obtained on an in-house diffractometer (ESI $\dagger$ ). Both coordination polymers are two-dimensional and crystallize in non-centrosymmetric space group (C2) with similar unit cell parameters having isomorphous structures. Due to the hydrogen bonds between adjacent coordination polymers and certain effect of the bulky phenyl group of the phenylalanine moiety, a twofold interpenetrated structure is determined.

Such a structural feature has not yet been observed in metalpeptide frameworks, and it is another step towards the design of these materials, providing another insight of the influence of the side chain group of peptides on thermal stability of the final products.

\section{Acknowledgements}

We appreciate financial support from Croatian Ministry of Science, Education and Sport.

\section{Notes and references}

1 S. Kitagawa, R. Kitaura and S.-I. Noro, Angew. Chem., Int. Ed., 2004, 43, 2334.

2 A. U. Czaja, N. Trukhan and U. Müller, Coord. Chem. Rev., 2009, 253, 3042.

3 P. Silva, S. M. F. Vilela, J. P. C. Tome and F. A. Almeida Paz, Chem. Soc. Rev., 2009, 38, 1284.

4 R. J. Kuppler, D. J. Timmons, Q.-R. Fang, J.-R. Li, T. A. Makal, M. D. Young, D. Yuan, D. Zhao, W. J. Zhuang and H.-C. Zhou, Chem. Soc. Rev., 2015, 44, 6774.

5 X. Zhang, W. Wang, Z. Hu, G. Wang and K. Uvdal, Coord. Chem. Rev., 2015, 284, 206.

6 C. Wang, M. Zheng and W. Lin, J. Phys. Chem. Lett., 2011, 2, 1701.

7 P. Horcajada, R. Gref, T. Baati, P. K. Allan, G. Maurin, P. Couvreur, G. Ferey, R. E. Morris and C. Serre, Chem. Rev., 2012, 112, 1232.

8 J. della Rocca, D. Liu and W. Lin, Acc. Chem. Res., 2011, 44, 957.

9 V. Lillo and J. R. Galán-Masca, Dalton Trans., 2014, 43, 9821. 
10 J. Rabone, Y.-F. Yue, S. Y. Chong, K. C. Stylianou, J. Bacsa, D. Bradshaw, G. R. Darling, N. G. Berry, Y. Z. Khimyak, A. Y. Ganin, P. Wiper, J. B. Claridge and M. J. Rosseinsky, Science, 2010, 329, 1053.

11 C. Marti-Gastaldo, J. E. Warren, K. C. Stylianou, N. L. O. Flack and M. J. Rosseinsky, Angew. Chem., Int. Ed., 2012, 51, 11044.

12 C. Marti-Gastaldo, D. Antypov, J. E. Warren, M. E. Briggs, P. A. Chater, P. V. Wiper, G. J. Miller, Y. Z. Khimyak, G. R. Darling, N. G. Berry and M. J. Rosseinsky, Nat. Chem., 2014, 6, 343.

13 A. P. Katsoulidis, K. S. Park, D. Antypov, C. Marti-Gastaldo, G. J. Miller, J. E. Warren, C. M. Robertson, F. Blanc, G. R. Darling, N. G. Berry, J. A. Purton, D. J. Adams and M. J. Rosseinsky, Angew. Chem., Int. Ed., 2014, 53, 193.

14 K. C. Stylianou, L. Gómez, I. Imaz, C. Verdugo-Escamilla, X. Ribas and D. Maspoch, Chem. - Eur. J., 2015, 21, 9964.
15 K. Nakamoto, Infrared and Raman Spectra of Inorganic and Coordination Compounds Part A: Theory and Applications in Inorganic Chemistry; Part B: Applications in Coordination, Organometallic, and Bioinorganic Chemistry, Wiley, New Jersey, 2009.

16 G. Facchin, M. H. Torre, E. Kremer, O. E. Piro, E. E. Castellano and E. J. Baran, Z. Naturforsch., 2000, 55b, 1157.

17 A. Mantion, L. Massüger, P. Rabu, C. Palivan, L. B. McCusker and A. Taubert, J. Am. Chem. Soc., 2008, 130, 2517.

18 B. B. Koleva, T. Kolev, S. Y. Zareva and M. Spilteller, J. Mol. Struct., 2007, 831, 165.

19 TOPAS version 4.2, Bruker-AXS, Karlsruhe, Germany.

20 G. S. Pawley, J. Appl. Cryst., 1986, 14, 357.

21 H. M. Rietveld, J. Appl. Crystallogr., 1969, 2, 65.

22 H.-Y. Lee, J. W. Kampf, K. S. Park and E. N. G. Marsh, Cryst. Growth Des., 2008, 8, 296. 